\title{
Waste and Biomass Valorization
}

\author{
Ange Nzihou, Editor-in-Chief
}

Published online: 26 February 2010

(C) Springer Science+Business Media B.V. 2010

I am delighted to announce the first journal dedicated solely to waste and biomass valorization. This journal will gather and disseminate cutting-edge research and experiences on the conversion of waste and biomass to energy, fuels and other useful materials, with particular focus on environmental indicators and sustainability goals. The concept that covers such areas is called valorization.

It is a field that is strongly characterized by inter- and multidisciplinarity. The quest for the recovery and generation of value in end-of-pipe processes demands cooperation by a large number of actors from various fields of Engineering Science including but not limited to Biochemical, Chemical, Civil, Environmental, Materials, and Health and Safety. Particular attention will be paid in bridging various fields related to waste and biomass.

This first issue comprises contributions from various fields and origins that highlight the research on diverse waste and biomass streams.

The issue starts with an introduction from Nzihou setting up the definition of valorization and discussing the related stakes, bottlenecks and challenges.

Among the topics developed in this issue, the production of fuel and energy is highlighted in particular. Various methods and streams are considered. Thygesen et al., discusses the microbial electrolysis cells (MECs) in the biorefinery for production of ethanol, $\mathrm{H}_{2}$ and phenolics. A

A. Nzihou ( $\square)$

Ecole des Mines d'Albi-Carmaux, RAPSODEE,

Campus Jarlard, 81013 Albi CT Cedex 09, France

e-mail: ange.nzihou@mines-albi.fr

A. Nzihou

Université de Toulouse, 118 route de Narbonne,

31077 Toulouse Cedex, France review on biohydrogen production from biomass and wastes via dark fermentation is proposed by Ntaikou et al. Another approach for the production of hydrogen from waste and biomass using cellulose and polyethylene is proposed by Zhang and Saito.

Vasudevan and $F u$ address current research on the synthesis of biodiesel, including the source of substrates, namely triglyceride and acyl-acceptors, reaction mechanism, catalysts for transesterification, solvent effects on biodiesel synthesis, especially in enzyme-catalyzed processes and, operations and various reactors type. The focus is on bioprocess.

The research in the use of agroindustrial residues has been known to be strong in Brazil for the last 15 years. Ferreira-Leitao and al. suggest a review on the inventory of the availability of these resources for the production of energy and useful materials.

Two review studies using thermal treatments are proposed. Stanmore discusses and examines current methods of burning bagasse for steam generation, and also the possibilities for steam gasification to produce a biogas suitable for combustion in gas turbines, while Castaldi and Themelis describe the current situation worldwide in wasteto-energy with some focus on the U.S. Description and discussion of the dominant technology, mass burn, as well as other next generation technologies are proposed.

Another key issue is the printed circuit cardboard because of the tremendous increase that has been observed annually of discarded quantities. The use of thermal treatment (pyrolysis) to treat waste printed circuit boards as a means to recover valuable materials, including the metals, an oil and gas product from the polymeric resin and glass fibre, is reviewed by Williams.

The valorization of waste for useful materials production is also addressed in this issue. Visakh and Thomas 
have reviewed the recent advances on the preparation and characterization of nanowhiskers from waste and biomass and their polymer nanocomposites. The emerging applications of these materials are also discussed. Wang provides an overview on fiber and textile recycling, focusing on the case of carpets, which account for a large part of textile waste. Another interesting contribution is proposed by Van Deventer et al. on geopolymers. The review on technical and commercial factors driving the growing adoption of geopolymer technology is explained and the understanding of the chemistry and mechanisms of geopolymer synthesis for the design of "green" concretes in industry with significant benefits in the emission of greenhouse gas emission $\left(\mathrm{CO}_{2}\right)$.

The management of emissions and pollutants is also addressed in this issue. Phosphates are known to be valuable materials for the remediation of a wide range of pollutants. For that, Daniels and Alexandratos propose a study on the design and synthesis of calcium phosphate based materials so called hydroxyapatite with organic modifiers as efficient media for the remediation of mineral or organic pollutants from waste. In the same line, Nzihou and Sharrock review the utilization of phosphate in the remediation and reuse of heavy metal polluted wastes and sites with a focus on heavy metal stabilization.

The journal will be published on a quarterly basis. We welcome new submissions of substantive research articles by people working in all fields related to waste and biomass valorization. A number of exciting issues are currently in preparation. Our aim is to sustain the high quality amply demonstrated by the papers published in this issue and thereby hope to strongly support those working in this rapidly expanding and important field. 